\title{
Spinal leptin contributes to the pathogenesis of neuropathic pain in rodents
}

\author{
Grewo Lim, Shuxing Wang, Yi Zhang, Yinghong Tian, and Jianren Mao \\ MGH Center for Translational Pain Research, Department of Anesthesia and Critical Care, Massachusetts General Hospital, \\ Harvard Medical School, Boston, Massachusetts, USA.
}

\begin{abstract}
Pain after nerve injury, a phenomenon referred to as neuropathic pain, is a debilitating clinical condition, but the underlying mechanisms remain unclear. As leptin, an adipocytokine produced mainly by nonneuronal tissue, has been implicated in the regulation of neuronal functions, we examined the role of leptin in neuropathic pain using a rat model of the condition chronic constriction sciatic nerve injury (CCI). We report that leptin critically contributed to pain behaviors following CCI. Specifically, spinal administration of a leptin antagonist prevented and reversed neuropathic pain behaviors in rats. Further examination revealed that levels of both leptin and the long form of the leptin receptor $(\mathrm{Ob}-\mathrm{Rb})$ were substantially increased within the ipsilateral spinal cord dorsal horn after peripheral nerve injury. Mechanistic studies showed that leptin upregulated the expression of both the spinal NMDA receptor and IL-1 $\beta$ through the JAK/STAT pathway. Furthermore, these CCI-induced behavioral and cellular responses were diminished in leptin-deficient mice and mimicked by spinal administration of exogenous leptin in naive rats. Our findings reveal a critical role for spinal leptin in the pathogenesis of neuropathic pain and suggest what we believe to be a novel form of nonneuronal and neuronal interactions in the mechanisms of pathological pain.
\end{abstract}

\section{Introduction}

Pain resulting from injury to the nervous system (neuropathic pain) has several salient clinical features, including hyperalgesia and allodynia beyond the dermatome distribution. Both peripheral and central mechanisms, including glial activation and release of proinflammatory cytokines, have been proposed for the pathogenesis of neuropathic pain (1-3). Despite recent progress, the mechanisms underlying clinical features of neuropathic pain remain unclear. Leptin is an adipocytokine produced mainly by white adipose tissue and well known for its role in metabolic regulation and obesity (4-8). A growing body of evidence indicates that leptin has broad roles in the regulation of neuronal functions $(3,9-11)$. Furthermore, leptin's signal transduction pathways have much in common with those of proinflammatory cytokines $(6,8,12)$.

Recent clinical reports suggest that there might be a link between the plasma leptin level and tissue injury. For example, patients with spinal cord injury, chronic angina pectoris, or acute myocardial infarction display a higher than normal plasma leptin level (13-15). In laboratory animals, intraperitoneal injection of exogenous leptin lowers the hot plate withdrawal latency in mice, although intracerebroventricular injection of leptin does not alter the hot plate test in rats (16). Moreover, mice with the leptin receptor null mutation $(d b / d b)$ demonstrate a decreased sensitivity to mechanical stimulation and a decreased nociceptive response in the affected hind paw during the second phase of a formalin test (17). These data suggest that leptin may have an important and yet unknown role in the mechanisms of pain.

We explored the possibilities that (a) the spinal effect of leptin would critically regulate neuropathic pain behaviors in a rat model

Conflict of interest: The authors have declared that no conflict of interest exists.

Nonstandard abbreviations used: CCI, chronic constriction sciatic nerve injury; CSF, cerebrospinal fluid; GFAP, glial fibrillary acidic protein; NMDAR, NMDA receptor; Ob-Rb, long form of the leptin receptor; p-STAT3, phosphorylated STAT3. Citation for this article: J. Clin. Invest. 119:295-304 (2009). doi:10.1172/JCI36785. of chronic constriction sciatic nerve injury (CCI) and (b) the proposed leptin effect would be mediated by leptin-dependent downstream cellular responses, including the upregulated expression of spinal NMDA receptors (NMDARs) and increased production of proinflammatory cytokines such as IL- $1 \beta$ through the JAK/STAT pathway. Our results indicate that spinal leptin may play an important role in the cellular mechanisms of neuropathic pain.

\section{Results}

Spinal leptin critically contributes to neuropathic pain behaviors. To determine whether blocking the spinal leptin effect would prevent the development of pain behaviors after CCI, a rat recombinant leptin antagonist $(18,19)$ was administered intrathecally once daily for 7 days beginning immediately after CCI or sham operation. This treatment regimen prevented the development of thermal hyperalgesia (Figure 1A) and mechanical allodynia (Figure 1C) on the hind paw affected by CCI in a dose-dependent manner $(4 \mu \mathrm{g}=2 \mu \mathrm{g}$ $>1 \mu \mathrm{g}=0.5 \mu \mathrm{g}=$ vehicle) when tested at 60 minutes after administration on days $1,3,5$, and 7 , as compared with the vehicle group $(n=6 ; P<0.05)$. Leptin antagonist $(2$ or $4 \mu \mathrm{g})$ slightly increased the thermal nociceptive threshold but not the mechanical nociceptive threshold on the hind paw affected by CCI (Figure 1, B and D; $P>0.05)$. In addition, the leptin antagonist did not change the baseline thermal or mechanical nociceptive threshold in rats that underwent sham operations (Figure $1, \mathrm{E}$ and $\mathrm{F} ; n=6 ; P>0.05$ ).

Blocking the spinal leptin effect also reversed established neuropathic pain behaviors in CCI rats. A single intrathecal administration of leptin antagonist $(3 \mu \mathrm{g})$ but not vehicle was shown to attenuate both thermal hyperalgesia and mechanical allodynia on day 7 after CCI at 60 minutes after the leptin antagonist treatment (Figure $1, \mathrm{G}$ and $\mathrm{H} ; n=6 ; P<0.05$ ). These data indicate that spinal leptin plays a critical role in pain behaviors induced by CCI.

Spinal leptin content is increased after CCI. While the basal leptin expression within the spinal cord dorsal horn did not differ between CCI and sham-operated rats, the leptin expression (West- 

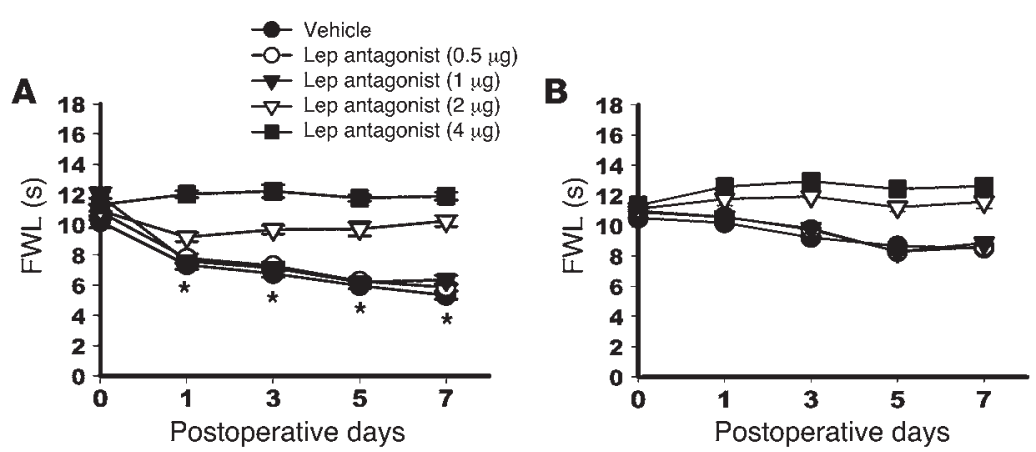

\section{Figure 1}

Effect of spinal leptin on neuropathic pain behaviors. (A-F) Intrathecal treatment with a leptin antagonist, once daily for 7 days, $(4 \mu \mathrm{g}=2 \mu \mathrm{g}>1 \mu \mathrm{g}=0.5 \mu \mathrm{g}$ $=$ vehicle) prevented the development of thermal hyperalgesia (A) and mechanical allodynia (C) on the hind paw ipsilateral to $\mathrm{CCl}$ on days $1,3,5$, and 7 in a dose-dependent manner. Leptin antagonist (2 or $4 \mu \mathrm{g})$ slightly increased the thermal nociceptive threshold but not the mechanical nociceptive threshold on the hind paw contralateral to $\mathrm{CCl}$ (B and $\mathbf{D}$ ). Leptin antagonist did not change the thermal and mechanical nociceptive threshold in sham-operated rats ( $\mathbf{E}$ and $\mathbf{F})$. ( $\mathbf{G}$ and $\mathbf{H}$ ) A single intrathecal administration of leptin antagonist $(3 \mu \mathrm{g})$ on day 7 attenuated both thermal hyperalgesia and mechanical allodynia at 60 minutes after the treatment. Lep, leptin; FWL, foot-withdrawal latency. Data are shown as mean \pm SD. ${ }^{\star} P<0.05$ versus vehicle.

cord dorsal horn as detected by semiquantitative RTPCR (Figure 2D; $n=5$ ). These findings were further confirmed by quantitative real-time RT-PCR using the same tissue samples from $\mathrm{CCI}$ and sham-operated rats (Figure $2 \mathrm{E} ; n=5 ; P<0.05$ ). In addition, a substantial increase in the leptin immunoreactivity was found on day 7 within the ipsilateral as opposed to the contralateral spinal cord dorsal horn of CCI rats (Figure 2F). Collectively, these results demonstrate a time-dependent increase in spinal leptin content and suggest possible de novo leptin production within the spinal cord dorsal horn after CCI.

Spinal leptin receptor expression is upregulated after CCI. Among leptin receptor (Ob-R) isoforms identified by alternate splicing of the $d b$ (Lepr) gene, the long form of the leptin receptor (Ob-Rb) is considered to be responsible for the majority of leptin functions (11, $20,21)$. Therefore, we selectively examined Ob-Rb expression in the spinal cord dorsal horn with or without CCI. CCI but not sham operation significantly increased Ob-Rb mRNA expression within the ipsilateral spinal cord dorsal horn on day 7 , as detected by semiquantitative RT-PCR (Figure $3 \mathrm{~A} ; n=5$ ) and confirmed by quantitative real-time RT-PCR using the same tissue samples from CCI and shamoperated rats (Figure 3B; $n=5 ; P<0.05$ ). A similar

ern blot) in the ipsilateral spinal cord dorsal horn was significantly increased on day 7 after CCI but not sham operation (Figure 2A; $n=6 ; P<0.05)$. The statistically significant increase in leptin expression was detected on days 3, 5, and 7 in CCI rats as compared with sham-operated rats within the ipsilateral but not contralateral spinal cord dorsal horn (Figure 2B; $n=5 ; P<0.05$ ). Since leptin is produced mainly by white adipose tissue and transported to the central nervous system in the absence of tissue injury (11), we sought to determine whether the plasma versus cerebrospinal fluid (CSF) leptin content would change after CCI using ELISA. As compared with sham-operated rats, CCI rats displayed a significant increase in the leptin content of CSF but not of plasma on day 7 (Figure 2C; $n=6 ; P<0.05$ ), consistent with the spinal leptin effect on pain behaviors at this time point after CCI.

Moreover, there was a basal expression of spinal leptin mRNA, which was increased on day 7 after CCI within the ipsilateral spinal increase in $\mathrm{Ob}-\mathrm{Rb}$ protein expression (Western blot) was also found within the ipsilateral but not contralateral spinal cord dorsal horn of CCI rats (Figure 3, C and D; $n=5 ; P<0.05$ ), which showed a time course similar to that of the spinal leptin increase after CCI (Figure $3 \mathrm{D} ; n=5 ; P<0.05)$. Furthermore, Ob-Rb immunoreactivity was topographically increased in the ipsilateral spinal cord dorsal horn of CCI rats as compared with sham-operated rats (Figure 3E). Spinal Ob-Rb immunoreactivity was colocalized primarily with NeuN (a neuronal marker) and, to a lesser extent, with glial fibrillary acidic protein (GFAP, an astrocyte marker) (Figure $3 \mathrm{~F}$ ), indicating that CCI induced the upregulation of primarily neuronal leptin receptors within the ipsilateral spinal cord dorsal horn.

Leptin induces the upregulation of spinal NMDAR and IL-1 $\beta$ via JAK2 and STAT3. To explore the cellular mechanisms underlying the spinal leptin effect on neuropathic pain, we first sought to determine whether the expression of JAK2 (a JAK isoform), STAT3 
A
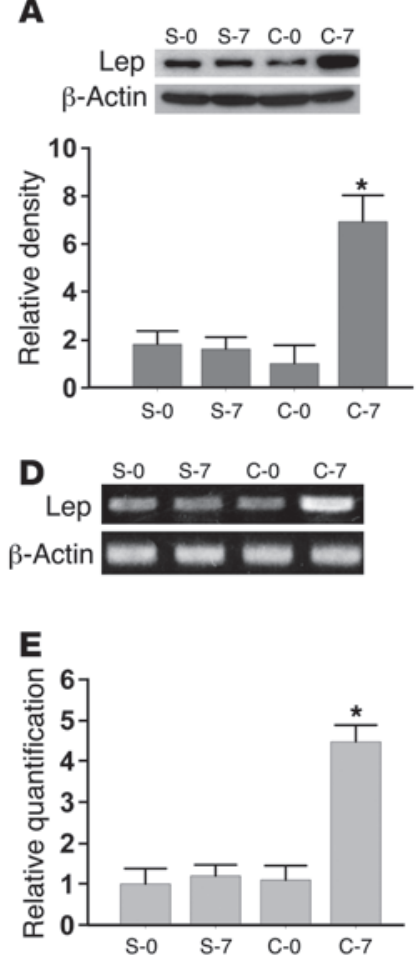

B

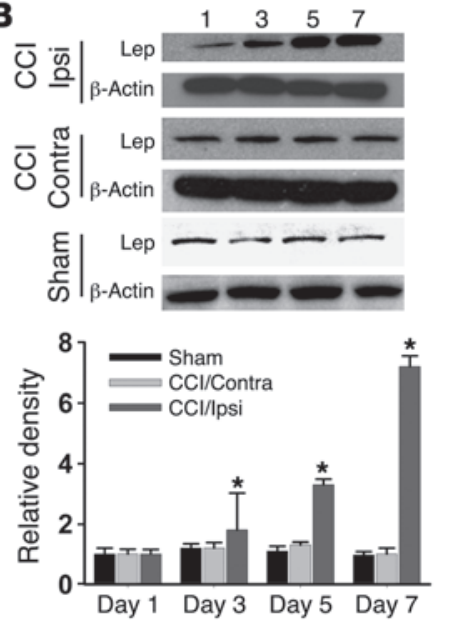

$\mathbf{F}$
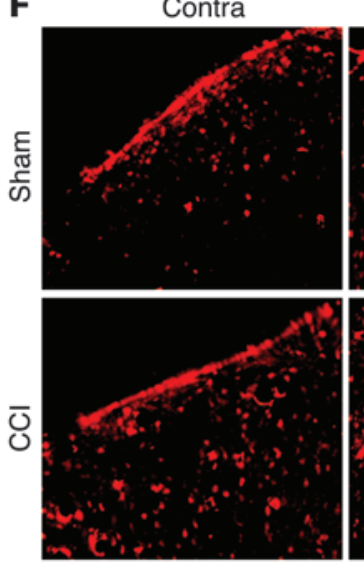

C

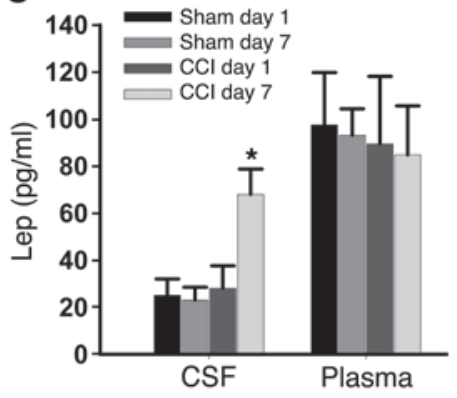

Ipsi

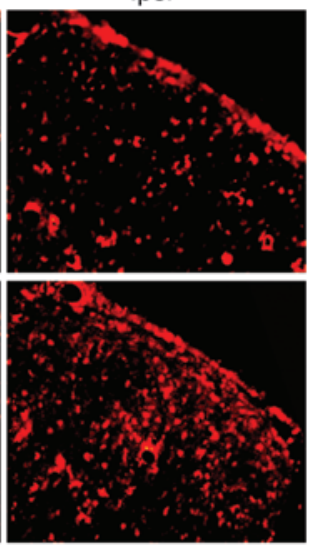

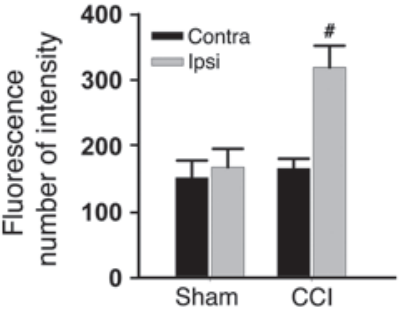

Figure 2

Increase in spinal leptin expression. (A and B) Leptin expression (Western blot) was increased after CCl in the ipsilateral (Ipsi) spinal cord dorsal horn but not in the contralateral (Contra) spinal cord dorsal horn. (C) CCl rats displayed a significant increase in CSF but not plasma leptin content on day 7. ( $\mathbf{D}$ and $\mathbf{E}$ ) Leptin mRNA expression was increased on day 7 after CCl within the ipsilateral spinal cord dorsal horn as detected by semiquantitative RT-PCR (D) and quantitative real-time RT-PCR (E). S-0, sham-operated rats on day 0; S-7, sham-operated rats on 7; C-0, $\mathrm{CCl}$ rats on day $0 ; \mathrm{C}-7, \mathrm{CCl}$ rats on day 7 . $\beta$-Actin was used as a loading control. (F) Leptin immunoreactivity was increased on day 7 within the ipsilateral compared with the contralateral spinal cord dorsal horn of $\mathrm{CCl}$ rats. Scale bar: $120 \mu \mathrm{m}$. Histogram shows density measurement of immunofluorescent images $(n=5)$. Data are shown as mean $\pm \mathrm{SD} .{ }^{*} P<0.05$ versus sham; $\# P<0.05$ versus contralateral.

(a STAT family member), and/or phosphorylated STAT3 (p-STAT3; activated STAT3) would be changed after CCI because JAK2 and STAT3 have been shown to play a critical role in leptin-dependent signal transduction pathways $(6,9,21,22)$. The results demonstrated that the expression (Western blot) of JAK2 and p-STAT3 was significantly increased, whereas STAT3 expression was moderately decreased, on day 7 within the ipsilateral spinal cord dorsal horn of CCI rats as compared with sham-operated rats (Figure 4, A and B; $n=6 ; P<0.05)$. This altered expression of JAK2, STAT3, and p-STAT3 was prevented by once daily intrathecal administration of leptin antagonist $(3 \mu \mathrm{g})$ for 7 postoperative days (Figure 4, A and $\mathrm{B} ; n=6 ; P<0.05)$, whereas the leptin antagonist alone moderately decreased the basal expression of JAK2 but not STAT3 or p-STAT3 in sham-operated rats (Figure 4, A and B). Significantly, CCI induced the upregulation of the NR1 subunit of NMDAR and IL- $1 \beta$ within the ipsilateral spinal cord dorsal horn on day 7 , which was prevented by the same intrathecal leptin antagonist treatment (Figure 4, C and D; $n=6 ; P<0.05$ ).
These results indicate that there was a leptin-dependent upregulation of spinal NMDAR and IL- $1 \beta$ after CCI. To confirm a direct spinal leptin effect and the role of JAK and STAT in this process, we utilized an in vitro organotypic lumbar spinal cord culture preparation taken from young (postnatal day 8 ) naive rats $(23,24)$. After the spinal cord culture was established for 1 week, the culture medium was replaced with a medium containing leptin $(100 \mathrm{ng} / \mathrm{ml})$ or vehicle for 5 or 72 hours (25). Exposure to exogenous leptin upregulated the expression of NR1 and IL-1 $\beta$ in the spinal cord tissue culture (Western blot) and increased the IL-1 $\beta$ content in the culture medium (ELISA) in a time-dependent manner, as compared with the vehicle group (Figure $4, \mathrm{E}-\mathrm{G} ; n=5$; each $P<0.05$ ). Moreover, adding AG 490 (a JAK/STAT inhibitor, $6 \mathrm{ng} / \mathrm{ml}$ ) (26) into the leptin $(100 \mathrm{ng} / \mathrm{ml})$ culture medium for 72 hours significantly diminished the upregulation of NR1 and IL-1 $\beta$ (Figure 4, H and I; $n=5$; $P<0.05)$. Exposure to leptin also increased the expression primarily of microglia in the spinal cord tissue culture (Figure 4J), suggesting a possible glial source of the IL- $1 \beta$ increase after the leptin exposure. 
A

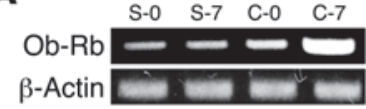

B

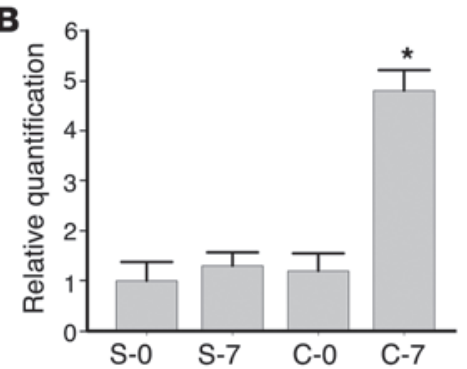

E
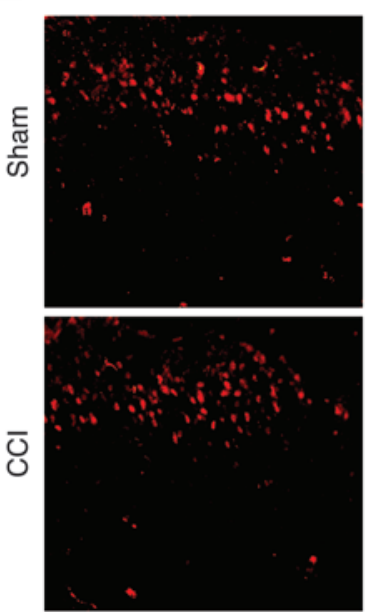

C
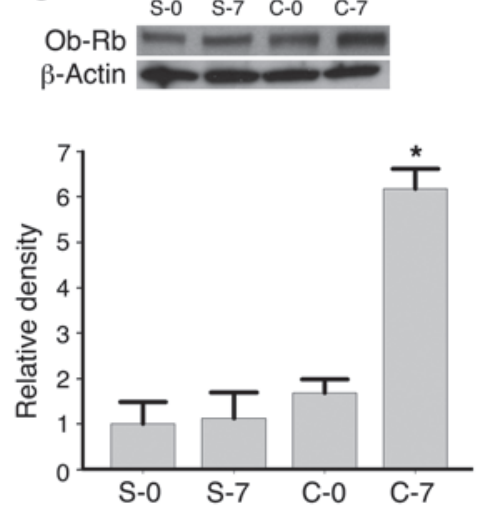

Ipsi

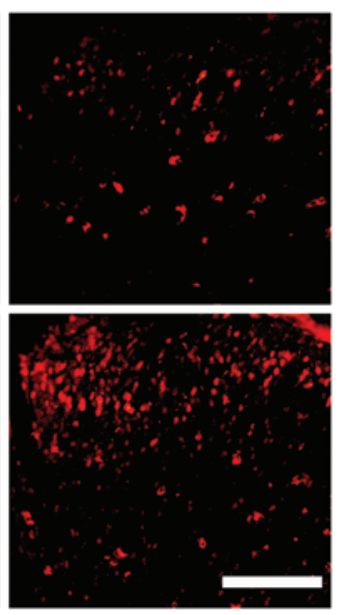

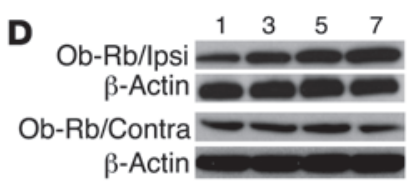

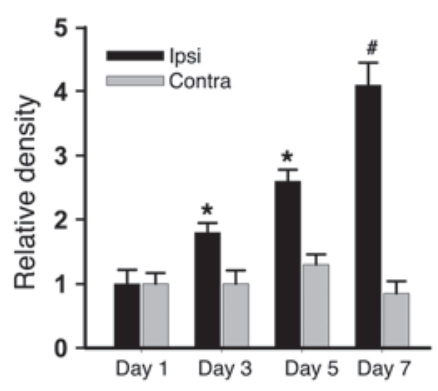

F Ob-Rb/NeuN
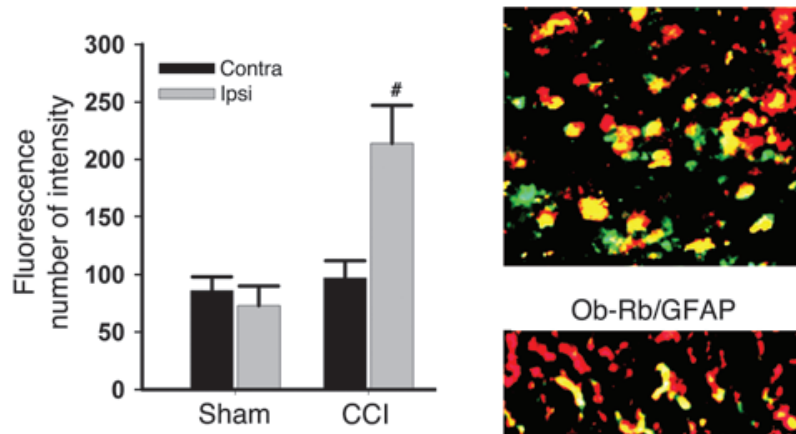

Ob-Rb/GFAP

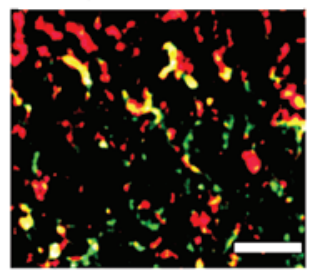

Figure 3

Upregulation of spinal leptin receptors. $\mathrm{CCl}$ increased $\mathrm{Ob}-\mathrm{Rb}$ mRNA expression within the ipsilateral spinal cord dorsal horn on day 7 but not on the contralateral side, as detected by semiquantitative RT-PCR $(\mathbf{A})$ and confirmed by quantitative real-time RT-PCR (B). Ob-Rb expression was also increased on day 7 , as determined by Western blot within the ipsilateral spinal cord dorsal horn of $\mathrm{CCl}$ rats $(\mathbf{C})$, with a time course similar to that of the spinal leptin increase after $\mathrm{CCl}$ (D). $\beta$-Actin was used as a loading control. (E) Ob-Rb immunoreactivity was increased in the ipsilateral spinal cord dorsal horn of $\mathrm{CCl}$ rats. Histogram shows density measurement of immunofluorescent images $(n=5)$. Scale bar: $120 \mu \mathrm{m}$. (F) $\mathrm{Ob}-\mathrm{Rb}$ immunoreactivity was colocalized primarily with NeuN and to a lesser extent with GFAP. Scale bar: $60 \mu \mathrm{m}$. Data are shown as mean \pm SD. ${ }^{*} P<0.05$ versus control; $\# P<0.05$ versus contralateral.

Furthermore, the NMDA-induced $(20 \mu \mathrm{M})$ current, recorded from the superficial layers of the spinal cord dorsal horn, was substantially enhanced after leptin $(100 \mathrm{nM})$ was added into the bath solution (Figure 4K). The enhanced NMDA current was recovered at 30 minutes after the leptin washout (Figure $4 \mathrm{~K}$ ), lending further support to a direct effect of leptin at the spinal level. Together with the in vivo results, these findings support a cellular link between the leptin-dependent activation of JAK2/STAT3 and their downstream effectors (NMDAR and IL-1 $\beta$ ) at the spinal level.

Leptin gene mutation abolishes CCI-induced behavioral and cellular changes. To further confirm the role of leptin in neuropathic pain, leptin-deficient $o b / o b$ mice were used in the following experiments. Thermal hyperalgesia of the ipsilateral hind paw was not seen in $o b / o b$ mice when they were examined on days $1,3,5$, and 7 after CCI (Figure 5A; $n=6 ; P<0.05$ ), while it was seen in the matched wild-type mice. Results in the $o b / o b$ mice were similar to those observed in CCI rats treated with intrathecal leptin antagonist
(Figure 1A). Consistent with the decreased sensitivity to mechanical stimulation in mice with the leptin receptor gene mutation (17), ob/ob mice also showed a higher baseline nociceptive threshold to mechanical stimulation than that in wild-type mice (Figure $5, \mathrm{C}$ and $\mathrm{D}$ ). Despite the difference in the baseline mechanical nociceptive threshold between $o b / o b$ and wild-type mice, CCI induced mechanical allodynia in the ipsilateral hind paws of wild-type but not $o b / o b$ mice (Figure 5, C and D; $n=6 ; P<0.05$ ). CCI did not change the thermal and mechanical nociceptive threshold in the contralateral hind paws of either $o b / o b$ or wild-type mice (Figure 5, $\mathrm{B}$ and $\mathrm{D} ; n=6 ; P>0.05)$.

Using a mouse-specific antibody, we did not detect leptin expression within the spinal cord dorsal horn of $o b / o b$ mice (Figure 5, E and $\mathrm{F} ; n=6 ; P<0.05$ ), although a low level of leptin expression was detected in $o b / o b$ mice using a less selective antibody that recognizes both mouse and rat leptin $(27,28)$. Moreover, there was no increase in leptin expression on day 7 after CCI, as compared with that in 

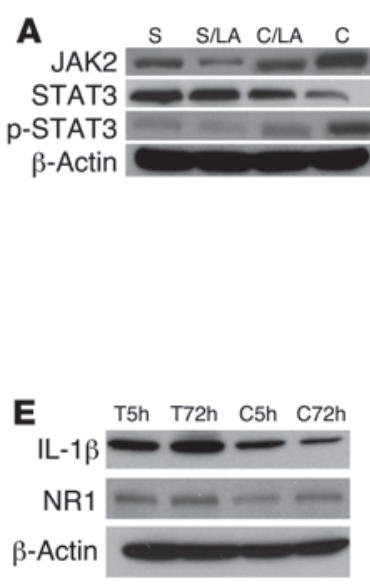

$\mathbf{J}$
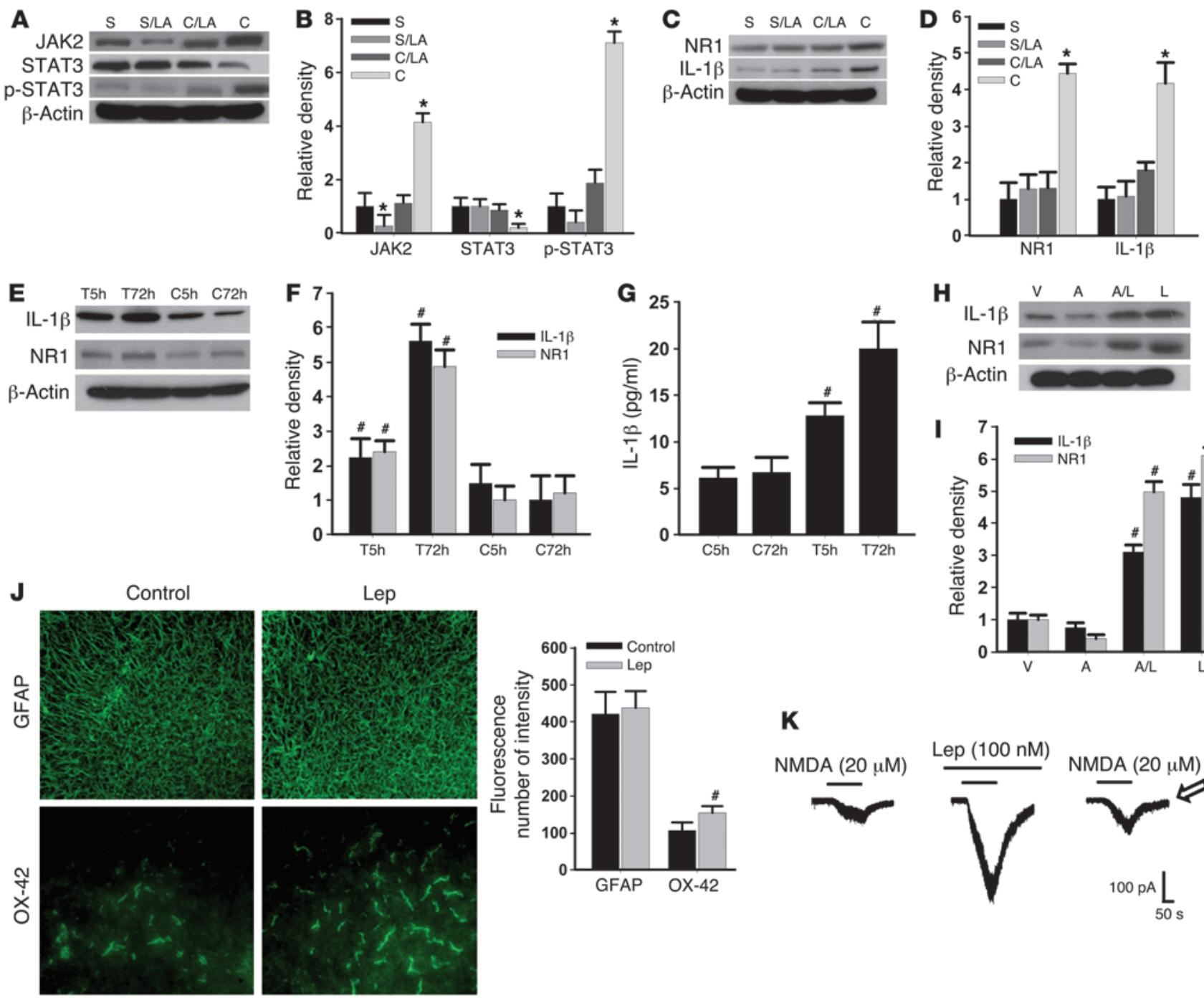

H

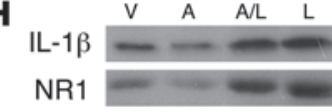

$\beta$-Actin
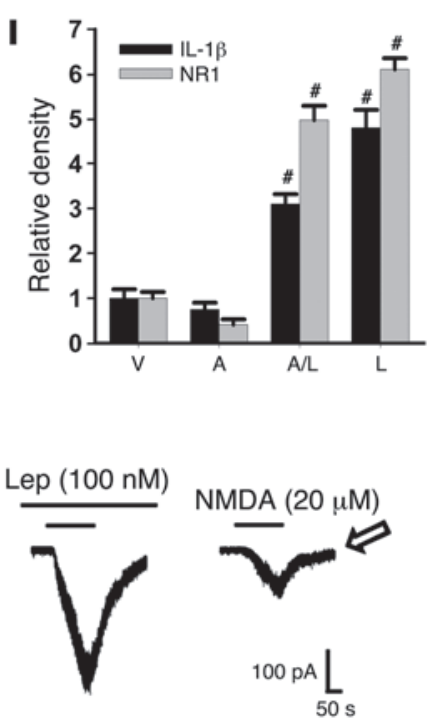

Figure 4

Role of JAK2 and STAT3 in the spinal leptin effect. (A-D) The expression (Western blot) of JAK2, p-STAT3, NR1, and IL-1 $\beta$ was increased, whereas STAT3 was decreased on day 7 in CCI rats. The altered expression of JAK2, STAT3, p-STAT3, NR1, and IL-1 $\beta$ was prevented by once daily intrathecal administration of leptin antagonist (LA, $3 \mu \mathrm{g}$ ) for 7 days. S, sham; C, CCI; LA, leptin antagonist. (E and F) Exposure to leptin $(100 \mathrm{ng} / \mathrm{ml})$ for 5 or 72 hours upregulated NR1 and IL- $1 \beta$ expression in an organotypic spinal tissue culture (Western blot) and increased IL- $1 \beta$ in the culture medium (ELISA) (G). T5h, leptin exposure for 5 hours; T72h, leptin exposure for 72 hours; C5h, vehicle exposure for 5 hours; C72h, vehicle exposure for 72 hours. (H and I) Adding AG $490(6 \mathrm{ng} / \mathrm{ml})$ into leptin (100 ng/ml) culture medium for 72 hours significantly reduced leptindependent NR1 and IL-1 $\beta$ upregulation. V, vehicle; A, AG 490; L, leptin. (J) Exposure to leptin increased the expression of microglia (OX-42) in the spinal tissue culture. Scale bars: $120 \mu \mathrm{m}$ (GFAP); $60 \mu \mathrm{m}$ (OX-42). Histogram shows density measurement of immunofluorescent images $(n=5)$. (K) NMDA-induced current was enhanced in the presence of leptin. Arrow indicates recovery of NMDA current at 30 minutes after leptin washout. Data are shown as mean $\pm \mathrm{SD} .{ }^{*} P<0.05$ versus sham; ${ }^{*} P<0.05$ versus control.

wild-type mice (Figure 5, E and F; $n=6 ; P>0.05$ ). Significantly, the basal expression of Ob-Rb, JAK2, p-STAT3, NR1, and IL-1 $\beta$ were all diminished within the spinal cord dorsal horn of $o b / o b$ mice as compared with their wild-type counterparts (Figure 5, E and F; $n=6 ; P<0.05$ ). Moreover, while wild-type mice demonstrated the upregulated expression of Ob-Rb, JAK2, p-STAT3, NR1, and IL-1 $\beta$ within the ipsilateral spinal cord dorsal horn on day 7 after CCI (Figure 5, E and F; $n=6 ; P<0.05$ ), these changes were absent in $o b / o b$ mice (Figure 5, E and F; $n=6 ; P>0.05$ ). These data indicate that the leptin deficiency in $o b / o b$ mice resulted in the weakened response of a leptin-dependent signal transduction pathway, which in turn led to diminished downstream response (NMDAR and IL-1 $\beta$ ) and attenuated behavioral changes after CCI.

Administration of exogenous leptin mimics CCI-induced behavioral and cellular changes. To determine whether administration of exogenous leptin would mimic the behavioral and cellular responses observed after CCI, different groups of naive rats received (a) vehicle, (b) 50 $\mu \mathrm{g}$ leptin, (c) $50 \mu \mathrm{g}$ leptin plus $1 \mu \mathrm{g}$ AG 490, (d) $50 \mu \mathrm{g}$ leptin plus $5 \mu \mathrm{g}$ AG 490, or (e) $5 \mu \mathrm{g} \mathrm{AG} 490$, given intrathecally once daily for 7 days. On day 7 , intrathecal leptin induced thermal hyperalgesia and mechanical allodynia in naive rats similar to that seen in CCI rats (Figure 6, A and B; $n=5 ; P<0.05$ ). Leptin treatment also 

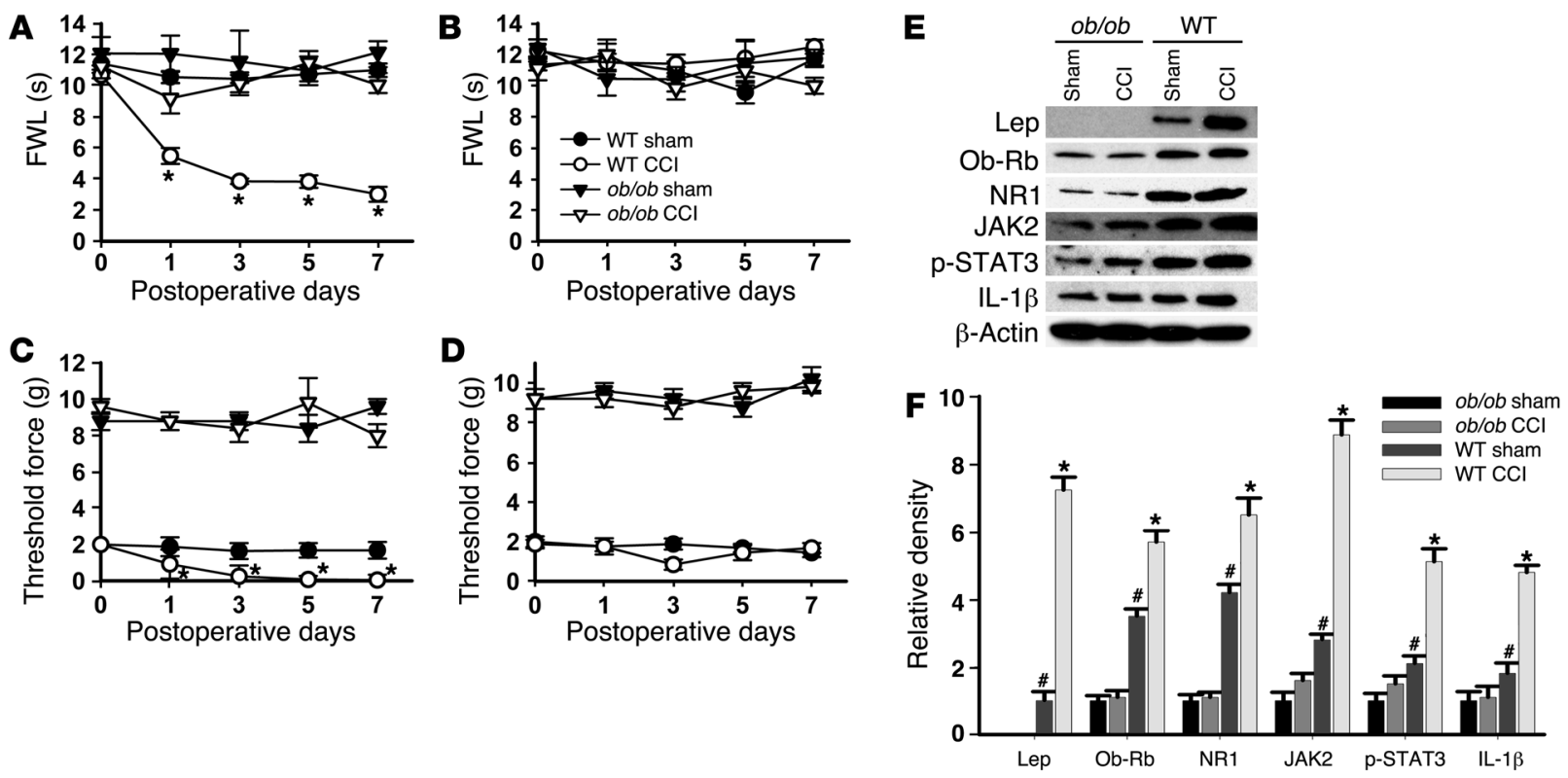

\section{Figure 5}

Effect of leptin gene mutation on behavioral and cellular changes. Thermal hyperalgesia (A) and mechanical allodynia (C) on ipsilateral hind paw was prevented in ob/ob mice, as shown on days 1,3,5, and 7. ob/ob mice also showed a higher baseline nociceptive threshold to mechanical stimulation compared with wild-type mice (C and D). $\mathrm{CCl}$ did not change the thermal and mechanical nociceptive threshold on the contralateral hind paw of either $o b / o b$ or wild-type mice (B and D). (E and F) ob/ob mice displayed a lack of leptin expression and a basal deficiency in Ob-Rb, JAK2, p-STAT3, NR1, and IL-1 $\beta$ expression within the spinal cord dorsal horn with no increase in expression on day 7 after CCI. Data are shown as mean $\pm \mathrm{SD}$. ${ }^{*} P<0.05$ versus sham; ${ }^{\#} P<0.05$ versus ob/ob.

induced upregulated NR1 and IL-1 $\beta$ expression (Western blot) within the spinal cord dorsal horn on day 7 in the same rats (Figure $6, \mathrm{C}$ and $\mathrm{D} ; n=5 ; P<0.05)$. Moreover, these behavioral and cellular changes were significantly attenuated by coadministration of leptin with the JAK/STAT inhibitor AG 490 (5 $\mu \mathrm{g}$ but not $1 \mu \mathrm{g}$ ) (Figure 6, A-C; $n=5 ; P<0.05)$. AG $490(5 \mu \mathrm{g})$ alone did not change the baseline nociceptive threshold (Figure 6 , A and $\mathrm{B} ; n=5$; $P<0.05$ ) but moderately decreased the basal expression of IL-1 $\beta$ and NR1 (Figure 6, C and D; $n=5 ; P<0.05$ ). These results indicate that spinal administration of exogenous leptin mimicked the CCI-induced behavioral and cellular responses mediated through the JAK/STAT pathway.

\section{Discussion}

We have demonstrated that (a) blockade of the spinal leptin effect prevented and reversed pain behaviors induced by peripheral nerve injury, (b) leptin and leptin receptors (Ob-Rb) were expressed within the spinal cord dorsal horn and upregulated after CCI in a timedependent manner, (c) leptin enhanced spinal NMDAR expression and IL-1 $\beta$ production through the JAK/STAT-mediated signal transduction pathway, and (d) leptin gene mutation and exogenous leptin abolished and mimicked CCI-induced behavioral and cellular changes, respectively. These results reveal a critical role for spinal leptin in the pathogenesis of neuropathic pain and a functional link between spinal leptin-dependent JAK/STAT activation and its downstream responses (NMDAR and IL-1 $\beta$ ) in this process. These findings also suggest a new form of nonneuronal and neuronal interactions in the mechanisms of pathological pain.

Leptin is a 167 -amino acid $(16 \mathrm{kDa})$ polypeptide hormone encoded by the obese gene (4), which has a high degree of homology across various species and is structurally analogous to cytokines. As an adipocytokine, leptin is produced mainly but not exclusively by white adipose tissue $(11,21)$ and transported across the blood brain barrier to the central nervous system $(9,29)$. Other peripheral leptin sources include gastric mucosa, bone marrow, mammary epithelium, and skeletal muscle (22). However, leptin mRNA expression has also been detected across various brain regions (30, 31 ), suggesting possible de novo leptin production within the central nervous system. In this study, we detected a basal level of spinal leptin mRNA and protein expression, which was upregulated within the ipsilateral spinal cord dorsal horn after CCI. CSF but not plasma leptin content also was increased on day 7 in CCI rats, although a possible change in the plasma leptin level at other postoperative time points could not be ruled out. Moreover, enhanced leptin immunoreactivity was topographically located within the ipsilateral as opposed to contralateral spinal cord dorsal horn of CCI rats. Together, these results provide strong evidence for a timedependent increase of spinal leptin content after CCI. The exact source or sources of the spinal leptin increase and the relationship between the peripheral and central leptin change following peripheral nerve injury remain to be examined in future studies.

Neuronal leptin receptors are expressed across broad brain regions including the hypothalamus, thalamus, hippocampus, and amygdala $(5-7,32-34)$ as well as in the dorsal root ganglion (35). This expression pattern is consistent with leptin's extensive neuronal functions on feeding behavior $(7,21,33)$, thermogenesis and neuroendocrine activity (8), memory processing (36), neuroprotection (37), synaptic plasticity (11), and tissue inflammation $(38,39)$. Our data, for what we believe is the first time, indicate that the spinal cord dorsal horn is a critical central locus 

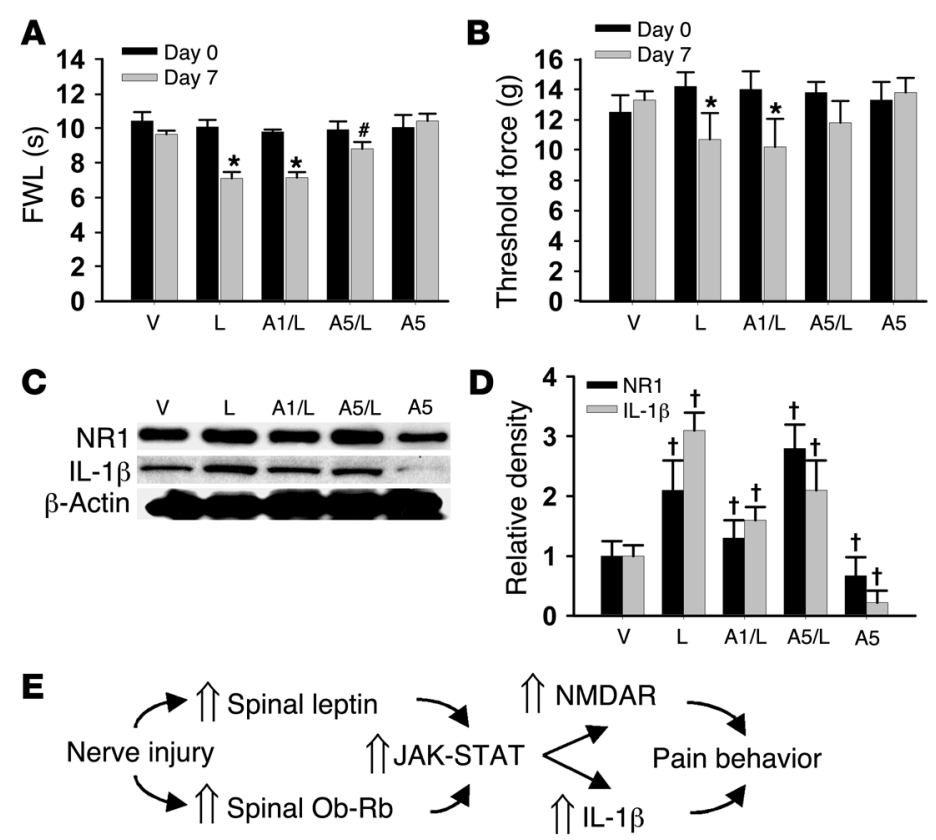

of leptin action in the mechanisms of neuropathic pain because (a) Ob-Rb was expressed within the spinal cord dorsal horn and colocalized primarily with neuronal cells, (b) Ob-Rb expression was upregulated after CCI within the superficial spinal cord dorsal horn (ipsilateral > contralateral), (c) there was a decrease in basal $\mathrm{Ob}-\mathrm{Rb}$ expression and a lack of Ob-Rb upregulation within the spinal cord dorsal horn in $o b / o b$ mice, and (d) spinal administration of a leptin antagonist prevented and reversed neuropathic pain behaviors in CCI rats.

Activation of JAK and STAT has been shown to be responsible for a number of leptin functions via targeted gene transcriptions, indicative of a genomic mechanism of leptin actions $(6,40)$. Our results support a critical relationship between activation of JAK/ STAT and the upregulation of spinal NMDAR and IL- $1 \beta$ within the spinal cord dorsal horn: (a) spinal JAK2 and p-STAT3 expression were upregulated after CCI, (b) inhibition of JAK/STAT activity at the spinal level diminished the upregulation of both NMDAR and IL-1 $\beta$, (c) spinal administration of exogenous leptin induced NMDAR and IL-1 $\beta$ expression in both in vitro organotypic spinal cord tissue culture and in vivo spinal cord dorsal horn, and (d) inhibition of spinal JAK/STAT activity also effectively prevented leptin-induced pain behaviors in naive rats. Thus, peripheral nerve injury activated a regulatory pathway critically contributory to the cellular mechanisms of neuropathic pain, which involves spinal leptin, JAK/STAT-mediated leptin signal transduction, and downstream cellular effectors such as NMDAR and IL-1 $\beta$ via leptin-dependent targeted gene transcription (Figure 6E). Although a regulatory effect of descending neural pathways could not be excluded in our in vivo experiments, the in vitro data using a spinal cord organotypic culture preparation suggest that leptin regulated NMDAR and IL- $1 \beta$ expression through its direct spinal action. It should be noted that the findings from the behavioral test (decreased nociceptive threshold after exogenous leptin) and electrophysiological experiment (enhanced NMDAR-mediated current in the presence of exogenous leptin) in naive rats suggest that exogenous leptin could mimic the effect of nerve injury on

\section{Figure 6}

Effect of exogenous leptin on behavioral and cellular changes. (A-D) Intrathecal leptin $(50 \mu \mathrm{g})$ treatment in naive rats, given once daily for 7 days, induced thermal hyperalgesia $(\mathbf{A})$ and mechanical allodynia (B) on day 7. Leptin treatment also induced upregulated NR1 and IL-1 $\beta$ expression (Western blot) within the spinal cord dorsal horn on day 7 (C and $\mathbf{D})$. The behavioral and cellular changes were attenuated by coadministration of leptin with the JAK/STAT inhibitor AG 490 (5 $\mu \mathrm{g}$ but not $1 \mu \mathrm{g})$. AG 490 $(5 \mu \mathrm{g})$ alone did not change the baseline nociceptive threshold ( $\mathbf{A}$ and B) but moderately decreased the basal expression of IL-1 $\beta$ and NR1. Amount of leptin indicated in all panels is $50 \mu \mathrm{m}$. A1, $1 \mu \mathrm{m}$ AG 490; A5, 5 um AG 490. (E) Flowchart illustrating a functional link among spinal leptin effect, leptin-dependent cellular responses, and neuropathic pain behaviors. Data are shown as mean \pm SD. ${ }^{*} P<0.05$ versus day 0 ; ${ }^{\#} P<0.05$ versus $A 1 /$ leptin $50 ;+P<0.05$ versus vehicle. spinal nociceptive processing. Thus, either the increase in endogenous leptin after nerve injury or administration of exogenous leptin in naive rats mimicking the nerve injury-induced leptin increase resulted in the exacerbated nociceptive response.

Of interest to note is that there were differences in the expression of total STAT3 and p-STAT3 on day 7 after CCI. A possible explanation is that the time course of changes in STAT3 versus p-STAT3 may differ after CCI, resulting in a differential expression of STAT3 and P-STAT3 on day 7. This possibility is supported by our preliminary experiment showing that the expression of both STAT3 and p-STAT3 was increased on days 1 and 4 after CCI as compared with that in the sham group (data not shown). On day 7, however, STAT3 expression was decreased while p-STAT3 expression remained increased. The mechanism of this differential expression between STAT3 and p-STAT3 remains to be examined. In addition, $o b / o b$ mice showed decreased basal expression of JAK2, STAT3, p-STAT3, NR1, and IL-1 $\beta$, suggesting a tonic effect of leptin on the expression of these cellular elements. However, leptin antagonist treatment at its current dose significantly reduced the basal expression of JAK2 but not other elements in rats. The differential effect of these experimental conditions on basal expression of the relevant cellular elements may be related to the degree and nature of the leptin deficiency (i.e., the genetic deficiency of leptin expression in $o b / o b$ mice versus a transient effect from the leptin antagonist treatment in rats). These possibilities need to be further examined in future studies.

The role of other leptin signal transduction pathways, such as MAPK and PI3K $(6,9,21,22)$, in the spinal leptin effect is yet to be examined. Moreover, leptin has been shown to modulate longterm potentiation through nongenomic mechanisms including enhanced NMDAR activity $(11,41)$. Conversely, blocking NMDAR activity prevents the stimulatory effect of leptin on the luteinizing hormone secretion (42). In this study, a transient application of leptin into spinal cord slice preparation substantially enhanced the NMDA current recorded from the superficial spinal cord dorsal horn. Since the leptin antagonist also reversed pain behaviors at 
60 minutes after a single intrathecal administration, it is possible that the effect of spinal leptin on the maintenance of neuropathic pain behaviors in CCI rats may be mediated through modulating NMDAR activity through a nongenomic mechanism (41).

Several clinical features of neuropathic pain are distinctively different from those of acute postoperative pain and inflammatory pain (1-3). Intractable clinical neuropathic pain results not only from abnormal activities of the nociceptive system but also from cognitive, affective, and hormonal changes. Our data suggest that leptin may be a unique target for new pharmacological interventions of neuropathic pain because leptin has a broad central role in neuronal functions, including neuroplasticity and neuroendocrine regulation (8). Future studies on the role of leptin in various aspects of neuropathic pain may help investigate the mechanisms underlying the multifactorial clinical presentation of intractable neuropathic pain.

\section{Methods}

Experimental animals. Male Sprague-Dawley rats (Charles River) weighing 275-350 g and $o b / o b\left(\mathrm{~B} 6 . \mathrm{V}-\mathrm{Lep}^{o b} / \mathrm{J}\right)$ and wild-type (C57BL/6J) mice at 8-10 weeks of age (The Jackson Laboratory) were used. Animals were individually housed (lights on from 7 am until $7 \mathrm{pm}$ ) with water and food available ad libitum. The animal protocol was approved by Massachusetts General Hospital Institutional Animal Care and Use Committee.

Drugs. Leptin antagonist was purchased from ARP, leptin from Abcam, and tyrphostin AG 490 from Sigma-Aldrich. Leptin antagonist and AG 490 were dissolved in $5 \%$ ethanol and 10\% DMSO (both diluted in normal saline), respectively. Either the diluted ethanol or DMSO solution was used as vehicle control. Leptin antagonist used in our experiments is a recombinant rat leptin (a polypeptide), resulting in L39A/D40A/F41A mutant, which was purified by chromatography. This leptin antagonist has been used to block the biological effect of leptin in previous in vivo and in vitro studies (43).

Surgical procedure. Rats or mice were anesthetized with pentobarbital $(50 \mathrm{mg} / \mathrm{kg}$, i.p.). CCI was produced according to the method of Bennett and Xie (44). In brief, one side of the common sciatic nerve was exposed and 2 (mice) or 4 (rats) loose ligatures (4-0 chromic gut) were made around the dissected nerve. Animals in sham groups underwent the same procedure except for nerve ligation. Some rats were also implanted with an intrathecal catheter (PE-10 tube) for drug delivery (45). Intrathecal injection was made using a microsyringe $(50 \mu \mathrm{l})$ in a $10-\mu \mathrm{l}$ volume followed by $10 \mu \mathrm{l}$ of saline to flush the catheter dead space.

Behavioral test. The foot-withdrawal test was used to assess hyperalgesia to radiant heat (46). Each animal underwent 3 trials, and the results from these trials were averaged to yield mean withdrawal latency. A set of von Frey filaments was used to examine mechanical allodynia using an up-and-down (in filament size) approach. A single filament was applied perpendicularly to the plantar surface of a hind paw. A threshold force of response (in grams) was defined as the first filament that evoked at least 2 paw withdrawals out of 5 applications $(45,47)$. Of note, the threshold force (about $2 \mathrm{~g}$ ) detected in our wild-type mice was higher than that reported in some studies $(0.2-0.6 \mathrm{~g})$ (48) but close to that in other studies $(2-4 \mathrm{~g})(49,50)$. These discrepancies could be due to the experimental handling of the mechanical allodynic test using von Frey filaments.

Immunohistochemistry. Under pentobarbital (50 mg/kg, i.p.) anesthesia, animals were perfused with saline through the ascending aorta followed by $4 \%$ paraformaldehyde containing $1.5 \%$ picric acid and $0.16 \mathrm{M} \mathrm{PBS}(\mathrm{pH}$ 7.2-7.4, $4^{\circ} \mathrm{C}$ ). Lumbar spinal cord segments were removed, post-fixed for $2-6$ hours, and kept overnight in $15 \%$ sucrose. Transverse spinal cord sections $(20 \mu \mathrm{m})$ were cut using a cryostat. Sections were blocked with $4 \%$ goat serum in $0.3 \%$ Triton $\mathrm{X}-100$ for 1 hour at room temperature and incu- bated for $24-48$ hours at $4{ }^{\circ} \mathrm{C}$ with one of the following primary antibodies: OX-42 (CD11b; Cymbus Biotechnology Ltd.): 1:500, mouse monoclonal; NeuN (Chemico; Millipore): 1:1,000, mouse monoclonal; GFAP (BD Biosciences - Pharmingen): 1:1000, mouse monoclonal; leptin (Santa Cruz Biotechnology Inc.): 1:200, rabbit polyclonal; or Ob-Rb (Alpha Diagnostic International): $1: 1,000$, rabbit polyclonal. Sections were then incubated for 1 hour at room temperature with FITC- or cyanine 3-conjugated secondary antibody (1:300; Jackson ImmunoResearch Laboratories Inc.). For colocalization of immunoreactivity, the incubation procedure was repeated with a second primary antibody and second secondary antibody. For control, primary antibodies were omitted in the process. Sections were examined with an Olympus fluorescence microscope, and images were captured with a digital camera (Olympus) and analyzed with Adobe PhotoShop version 7. The density of these sections was also measured using computer software (Image-Pro Plus; Media Cybernetics version 6) and analyzed by paired Waller-Duncan K-ratio $t$ tests.

Western blot analysis. Animals were sacrificed by decapitation under pentobarbital anesthesia. The ipsilateral lumbar spinal cord dorsal horn was separated from the contralateral lumbar spinal cord dorsal horn and homogenized in an SDS buffer containing a cocktail of proteinase inhibitors (Sigma-Aldrich). Samples were separated on an SDS-PAGE gel (4\%-15\% gradient gel; Bio-Rad) and transferred to PVDF membranes (Millipore). Membranes were blocked with $5 \%$ nonfat dried milk and incubated overnight $\left(4^{\circ} \mathrm{C}\right)$ with one of the following primary antibodies: leptin (Santa Cruz Biotechnology Inc.): 1:500, rabbit polyclonal against human, rat, and mouse; leptin (Chemicon; Millipore): 1:500, rabbit polyclonal against mouse only; NR1 (Novus Biologicals): 1:500, rabbit polyclonal; JAK2 (Santa Cruz Biotechnology Inc.): 1:500, rabbit polyclonal; STAT3 (Cell Signaling Technology): 1:1,000, rabbit polyclonal; p-STAT3 (Cell Signaling Technology): 1:1,000, rabbit polyclonal; Ob-Rb (Alpha Diagnostic International): 1:500, rabbit polyclonal; or IL-1 $\beta$ (R\&D Systems): 1:1,000, goat polyclonal. Membranes were then incubated for 1 hour at room temperature with an HRP-conjugated secondary antibody (1:7,000; Amersham). Blots were visualized in ECL solution (PerkinElmer) for 5 minutes and exposed to hyperfilms (Amersham) for 1-10 minutes. Blots were again incubated in a stripping buffer (67.5 mM Tris, $\mathrm{pH} 6.8,2 \% \mathrm{SDS}$, and $0.7 \% \beta$-mercaptoethanol) for 30 minutes at $50^{\circ} \mathrm{C}$ and reprobed with an anti- $\beta$-actin antibody (1:12,000, mouse monoclonal; Abcam) as loading control. Western blots were made in triplicate. Band density was measured and normalized against a loading control band.

Real-time RT-PCR. Total RNA was isolated using TRIzol reagent (Invitrogen). Two micrograms of total RNA was used to synthesize the first strand of cDNA using SuperScript III kit (Invitrogen) according to the manufacturer's protocol. cDNA was diluted by 10 -fold, and $1 \mu \mathrm{l}$ of the diluted cDNA was used in a 20- $\mu$ l PCR vessel. Real-time PCR was used to analyze the gene expression of leptin and Ob-Rb. $\beta$-Actin RNA gene expression was also measured as a control. PCR was performed by fluorogenic 5' nuclease assay-based TaqMan real-time RT-PCR by using the ABI PRISM 7900 Sequence Detection System (PerkinElmer). Amplification was performed using the following primers: 5'-TACAACCTCCTTGCACC ${ }^{\prime}$ (forward) and $5^{\prime}$-ACAATGCCGTGTTCAATGG-3' (reverse) for $\beta$-actin; 5'-GAGACCTCCTCCATGTGCTG-3' (forward) and 5'-CATTCAGGGCTAAGGTCCAA-3' (reverse) for leptin; and $5^{\prime}$-TGACCACTCCAGATTCCACA-3' (forward) and $5^{\prime}$-CCACTGTTTTCACGTTGCTG-3' (reverse) for $\mathrm{Ob}-\mathrm{Rb}$. PCR conditions used to amplify these genes were $94^{\circ} \mathrm{C}$ for $30 \mathrm{sec}-$ onds, $58^{\circ} \mathrm{C}$ for 20 seconds, and $72^{\circ} \mathrm{C}$ for 30 seconds, with the exception of $\beta$-actin, for which the annealing temperature was $55^{\circ} \mathrm{C}$. $\beta$-Actin was amplified over 35 cycles, and leptin and Ob-Rb were amplified over 40 cycles.

ELISA. A standard curve was generated for each assay using the reference set supplied in the leptin ELISA kit (R\&D Systems). Plasma or CSF 
samples were read using a microplate reader (BioTek) at wavelengths of $450-620 \mathrm{~nm}$. The content of IL-1 $\beta$ in the spinal cord explant incubation medium was assayed using an immunoassay kit based on the manufacturer's instructions (R\&D Systems). The sample concentration was calculated based on the standard curve.

Organotypic spinal cord culture. Organotypic spinal cord cultures were prepared using lumbar spinal cord slices from 8-day-old rat pups. Neonatal rat pups were decapitated, and the lumbar spinal cords were rapidly harvested and cultured using a modified method $(23,24)$. Spinal cords were collected under sterile conditions and immersed immediately in $4^{\circ} \mathrm{C}$ sterile buffer (Gey's balanced salt solution, Sigma-Aldrich; containing $6.4 \mathrm{mg} / \mathrm{ml}$ glucose). Meninges were carefully removed, and $350 \mu \mathrm{m}$ transverse spinal cord slices were made using a McIlwain tissue chopper (Vibratome). Slices were carefully placed on the surface of $30 \mathrm{~mm}$ Millicell-CM (Millipore) porous $(0.4 \mu \mathrm{m})$ membranes. These membranes were then placed in $35-\mathrm{mm}$ culture wells (BD) filled with $1 \mathrm{ml}$ of incubation medium consisting of $50 \%$ $\mathrm{vol} / \mathrm{vol}$ minimal essential medium containing $25 \mathrm{mM}$ HEPES, $25 \% \mathrm{vol} / \mathrm{vol}$ heat-inactivated horse serum, and $25 \% \mathrm{vol} / \mathrm{vol} \mathrm{HBSS}$ (Invitrogen) supplemented with D-glucose $(25.6 \mathrm{mg} / \mathrm{ml})$ and glutamine $(2 \mathrm{mM})$, at a final $\mathrm{pH}$ of 7.2. Slices were incubated at $37^{\circ} \mathrm{C}$ in a $5 \% \mathrm{CO}_{2} / 25 \%$ air-humidified environment. Culture medium was changed 3 times a week. Culture medium was collected for ELISA, and spinal cord slices were rinsed with PBS 3 times and collected in a lysis buffer $(0.15 \mathrm{M} \mathrm{NaCl}, 0.02 \mathrm{M}$ Tris- $\mathrm{HCl}$, and $0.001 \mathrm{M}$ EDTA) for either Western blot or immunohistochemistry.

Electrophysiological recording. Spinal cord slices $(250 \mu \mathrm{m})$ were prepared from postnatal day 18-20 rats and perfused with a medium (bubbled with $95 \% \mathrm{O}_{2}$ and $5 \% \mathrm{CO}_{2}$ ) containing $125 \mathrm{mM} \mathrm{NaCl}, 2.5 \mathrm{mM} \mathrm{KCl}, 26 \mathrm{mM} \mathrm{NaHCO}_{3}, 1.25$ $\mathrm{mM} \mathrm{NaH}_{2} \mathrm{PO}_{4}, 2 \mathrm{mM} \mathrm{CaCl}_{2}, 2 \mathrm{mM} \mathrm{MgCl}_{2}$, and $10 \mathrm{mM}$ D-glucose. Whole-cell recordings from the superficial spinal cord dorsal horn were obtained using electrodes (4-6 M $\Omega$ ) containing $140 \mathrm{mM} \mathrm{K}$-gluconate, $2 \mathrm{mM} \mathrm{MgCl}_{2}, 1 \mathrm{mM}$ $\mathrm{CaCl}_{2}, 11 \mathrm{mM}$ EGTA, $10 \mathrm{mM}$ HEPES, $5 \mathrm{mM} \mathrm{Mg}$-ATP, and $0.5 \mathrm{mM} \mathrm{Na}-\mathrm{GTP}$, $\mathrm{pH}$ 7.3. The NMDA current was evoked by ejecting $20 \mu \mathrm{M}$ NMDA and $10 \mu \mathrm{M}$ glycine in $\mathrm{Mg}^{2+}$-free artificial CSF for 150 seconds at a holding potential of $-70 \mathrm{mV}$. The ejection solution also contained $1 \mu \mathrm{M}$ strychnine, $10 \mu \mathrm{M}$ bicuculline, $10 \mu \mathrm{M}$ 2,3-dihydroxy-6-nitro-7-sulfamoyl-benzo[f]quinoxaline-2,3dione (NBQX), and $1 \mu \mathrm{M}$ tetrodotoxin. Once the baseline NMDA current was acquired, $100 \mathrm{nM}$ leptin was bath applied for 12 minutes before and during the next NMDA ejection. The leptin solution was then washed out over 30 minutes, and the NMDA current was again recorded for comparison. Recordings were made using an Axopatch 700B amplifier (Molecular Devices). Signals were filtered at $2 \mathrm{kHz}$, digitized at $10 \mathrm{kHz}$, acquired using a personal computer and pClamp software (version 9.02; Axon Instruments, Molecular Devices), and stored for later analysis. Input resistance was monitored throughout experiments. The mean series resistance for all cells was 25 $\mathrm{M} \Omega(n=30)$. Experiments were performed at room temperature $\left(22-25^{\circ} \mathrm{C}\right)$.

Statistics. All results are expressed as mean \pm SD. Foot-withdrawal latencies were analyzed using 2-way ANOVA repeated across test time points to detect overall differences among treatment groups. Whenever applicable, the data were also examined using 2-way ANOVA repeated across treatment groups to examine overall differences among test time points. In either case, when significant main effects were detected, the Waller-Duncan K-ratio $t$ test was performed to determine the between-group difference. The nonparametric Mann-Whitney $U$ test was used to determine differences in the threshold force in response to von Frey filament stimulation. Differences were considered to be statistically significant at the level of $\alpha=0.05$. In Western blot, RT-PCR, and ELISA analysis, differences were compared using 1-way ANOVA followed by the Waller-Duncan K-ratio $t$ tests. In all cases, $P<0.05$ was considered to be statistically significant.

\section{Acknowledgments}

This study was supported by NIH RO1 grants DE018214, DE018538, and NS45681 (to J. Mao). We would like to thank Kaiyuan Fu of Beijing University for his assistance in immunohistochemistry.

Received for publication July 15, 2008, and accepted in revised form November 12, 2008.

Address correspondence to: Jianren Mao, MGH Center for Translational Pain Research, Department of Anesthesia and Critical Care, WACC 324, Massachusetts General Hospital, Harvard Medical School, Boston, Massachusetts, USA. Phone: (617) 726-2338; Fax: (617) 724-8844; E-mail: jmao@partners.org.
1. DeLeo, J.A., Colburn, R.W., Nichols, M., and Malhotra, A. 1996. Interleukin-6-mediated hyperalgesia/allodynia and increased spinal IL-6 expression in a rat mononeuropathy model. J. Interferon Cytokine Res. 16:695-700.

2. Woolf, C.J., and Mannion, R.J. 1999. Neuropathic pain: aetiology, symptoms, mechanisms, and management. Lancet. 353:1959-1964.

3. Watkins, L.R., Milligan, E.D., and Maier, S.F. 2001. Glial activation: a driving force for pathological pain. Trends Neurosci. 24:450-455.

4. Zhang, Y., et al. 1994. Positional cloning of the mouse obese gene and its human homologue. Nature. 372:425-432.

5. Elmquist, J.K., Bjørbaek, C., Ahima, R.S., Flier, J.S., and Saper, C.B. 1998. Distributions of leptin receptor mRNA isoforms in the rat brain.J. Comp. Neurol. 395:535-547.

6. Schwartz, M.W., Woods, S.C., Porte, D., Jr., Seeley, R.J., and Baskin, D.G. 2000. Central nervous system control of food intake. Nature. 404:661-671.

7. Ahima, R.S., Qi, Y., Singhal, N.S., Jackson, M.B., and Scherer, P.E. 2006. Brain adipocytokine action and metabolic regulation. Diabetes. 55(Suppl. 2):S145-S154.

8. Elmquist, J.K., Maratos-Flier, E., Saper, C.B., and Flier, J.S. 1998. Unraveling the central nervous system pathways underlying responses to leptin. Nat. Neurosci. 1:445-450.

9. Banks, W.A. 2004. The many lives of leptin. Peptides.
25:331-338.

10. Palmiter, R.D. 2007. Is dopamine a physiologically relevant mediator of feeding behavior? Trends Neurosci. 30:375-381.

11. Harvey, J. 2007. Leptin: a diverse regulator of neuronal function. J. Neurochem. 100:307-313.

12. Guzik, T.J., Mangalat, D., and Korbut, R. 2006. Adipocytokines - novel link between inflammation and vascular function? J. Physiol. Pharmacol. 57:505-528.

13. Huang, T.S., Wang, Y.H., and Chen, S.Y. 2000. The relation of serum leptin to body mass index and to serum cortisol in men with spinal cord injury. Arch. Phys. Med. Rehabil. 81:1582-1586.

14. Jose, V.J., Mariappan, P., George, P.V., and Selvakumar, D. 2005. Serum leptin levels in acute myocardial infarction. Indian Heart J. 57:39-43.

15. Taneli, F., et al. 2006. Increased serum leptin concentrations in patients with chronic stable angina pectoris and ST-elevated myocardial infarction. Angiology. 57:267-272.

16. Kutlu, S., et al. 2003. Effects of central and peripheral administration of leptin on pain threshold in rats and mice. Neuro. Endocrinol. Lett. 24:193-196.

17. Wright, D.E., Johnson, M.S., Arnett, M.G., Smittkamp, S.E., and Ryals, J.M. 2007. Selective changes in nocifensive behavior despite normal cutaneous axon innervation in leptin receptor-null mutant (db/db) mice. J. Peripher. Nerv. Syst. 12:250-261.

18. Brunner, L., et al. 1999. A peptide leptin antagonist reduces food intake in rodents. Int. J. Obes. Relat. Metab. Disord. 23:463-469.

19. Zhang, J., Matheny, M.K., Tümer, N., Mitchell, M.K., and Scarpace, P.J. 2007. Leptin antagonist reveals that the normalization of caloric intake and the thermic effect of food after high-fat feeding are leptin dependent. Am. J. Physiol. Regul. Integr. Comp. Physiol. 292:R868-R874.

20. Tartaglia, L.A., et al. 1995. Identification and expression cloning of a leptin receptor, OB-R. Cell. 83:1263-1271.

21. Myers, M.G., Jr. 2004. Leptin receptor signaling and the regulation of mammalian physiology. Recent Prog. Horm. Res. 59:287-304.

22. Frühbeck, G. 2006. Intracellular sinalling pathways activated by leptin. Biochem. J. 393:7-20.

23. Rothstein, J.D., Jin, L., Dykes-Hoberg, M., and Kuncl, R.W. 1993. Chronic inhibition of glutamate uptake produces a model of slow neurotoxicity. Proc. Natl. Acad. Sci. U. S. A. 90:6591-6595.

24. Stoppini, L., Buchs, P., and Muller, D. 1991. A simple method for organotypic cultures of nervous tissue. J. Neurosci. Methods. 37:173-182.

25. Lin, S., et al. 2006. Leptin increases tissue inhibitor of metalloproteinase I (TIMP-1) gene expression by a specificity protein 1 /signal transducer and activator of transcription 3 mechanism. Mol. Endocrinol. 20:3376-3388.

26. Chen, C., Chang, Y.C., Liu, C.L., Chang, K.J., and Guo, I.C. 2006. Leptin-induced growth of human 
ZR-75-1 breast cancer cells is associated with upregulation of cyclin D1 and c-Myc and down-regulation of tumor suppressor p53 and p21WAF1/ CIP1. Breast Cancer Res. Treat 98:121-132.

27. Bhat, G., et al. 2006. Influence of a leptin deficiency on testicular morphology, germ cell apoptosis, and expression levels of apoptosis-related genes in the mouse. J. Androl. 27:302-310.

28. Macdougald, O.A., Hwang, C.S., Fan, H., and Lane, M.D. 1995. Regulated expression of the obese gene product (leptin) in white adipose tissue and 3T3-L1 adipocytes. Proc. Natl. Acad. Sci. U. S. A. 92:9034-9037.

29. Pan, W., and Kastin, A. 2007. Adipokines and the blood-brain barrier. Peptides. 28:1317-1330.

30. Morash, B., Li, A., Murphy, P., Wilkinson, M., and Ur, E. 1999. Leptin gene expression in the brain and pituitary gland. Endocrinology. 140:5995-5998.

31. Ur, E., Wilkinson, D.A., Morash, B.A., and Wilkinson, M. 2002. Leptin immunoreactivity is localized to neurons in rat brain. Neuroendocrinology. 75:264-272

32. Lin, J., et al. 2000. Long form leptin receptor mRNA expression in the brain, pituitary, and other tissues in the pig. Domest. Anim. Endocrinol. 19:53-61.

33. Cohen, P., et al. 2001. Selective deletion of leptin receptor in neurons leads to obesity. J. Clin. Invest 108:1113-1121.

34. Wilkinson, M., Brown, R., Imran, S.A., and Ur, E.
2007. Adipokine gene expression in brain and pituitary gland. Neuroendocrinology. 86:191-209.

35. Chen, H.P., Fan, J., and Cui, S. 2006. Detection and estrogen regulation of leptin receptor expression in rat dorsal root ganglion. Histochem. Cell Biol. 126:363-369

36. Farr, S.A., Banks, W.A., and Morley, J.E. 2006 Effects of leptin on memory processing. Peptides. 27:1420-1425

37. Tang, B.L. 2008. Leptin as a neuroprotective agent. Biochem. Biophys. Res. Commun. 368:181-185.

38. Bozkurt, A., Cakir, B., Ercan, F., and Yegen, B.C. 2003. Anti-inflammatory effects of leptin and cholecystokinin on acetic acid-induced colitis in rats: role of capsaicin-sensitive vagal afferent fibers. Regul. Pept. 116:109-118.

39. Härle, P., and Straub, R.H. 2006. Leptin is a link between adipose tissue and inflammation. Ann. N. Y. Acad. Sci. 1069:454-462.

40. Lavens, D., Piessevaux, J., and Tavernier, J. 2006 Review: negative regulation of leptin receptor signalling. Eur. Cytokine Netw. 17:211-219.

41. Shanley, L.J., Irving, A.J., and Harvey, J. 2001. Leptin enhances NMDA receptor function and modulates hippocampal synaptic plasticity. J. Neurosci. 21:RC186.

42. Carbone, S., et al. 2005. Leptin stimulates LH secretion in peripubertal male rats through NMDA receptors. Endocr. Res. 31:387-396.
43. Gertler, A. 2006. Development of leptin antagonistsand their potential use in experimental biology and medicine. Trends Endocrinol. Metab. 17:372-378.

44. Bennett, G., and Xie, Y. 1998. A peripheral mononeuropathy in rat that produces disorders of pain sensation like those seen in man. Pain. 33:87-107.

45. Mao, J., Price, D., Zhu, J., Lu, J., and Mayer, D. 1997. The inhibition of nitric oxide activated poly (ADP ribose) synthetase attenuates transsynaptic alteration of spinal cord dorsal horn neurons and neuropathic pain in the rat. Pain. 72:355-366.

46. Hargreaves, K., Dubner, R., Brown, F., Flores, C., and Joris, J. 1988. A new and sensitive method for measuring thermal nociception in cutaneous hyperalgesia. Pain. 32:77-88.

47. Tal, M., and Bennett, G.J. 1994. Extra-territorial pain in rats with a peripheral mononeuropathy: mechano-hyperalgesia and mechano-allodynia in the territory of an uninjured nerve. Pain. 57:375-382.

48. Uçeyler, N., et al. 2006. Heterozygous P0 deficiency protects mice from vincristine-induced polyneuropathy. J. Neurosci. Res. 84:37-46.

49. Li, X., and Clark, J.D. 2003. Heme oxygenase type 2 participates in the development of chronic inflammatory and neuropathic pain. J. Pain. 4:101-107.

50. Xu, M., et al. 2004. Neuropathic pain activates the endogenous kappa opioid system in mouse spinal cord and induces opioid receptor tolerance. J. Newrosci. 24:4576-4584. 